\title{
Mensaje del Presidente
}

\author{
David Szydlo
}

Presidente de la Sociedad Mexicana de Neurología y Psiquiatría

Estamos viviendo tiempos inmensamente interesantes. Los avances en la investigación, tanto en las áreas que estudian la mente, la psique, la conducta y las emociones, así como en el campo de la neurología, donde aquéllas comienzan a entrelazarse de manera incuestionable. Estas aproximaciones epistemológicas gestan conocimientos complejos que no solamente retan premisas pasadas tanto del funcionamiento del sistema nervioso como del aparato psíquico, sino que plantean avenidas inimaginables para aquéllos que se atreven a observarlos con una mente abierta y crítica. Las neurociencias, como algunos se refieren a ellas, en mi opinión erróneamente, tratan de englobar áreas del saber provenientes de la neurología y de la psiquiatría. Sin embargo, esta sumatoria de ciencias se ha vuelto contagiosa y hoy en día podemos agregar a la genética, la epigenética, la inmunología, la endocrinología y algunas otras ciencias sociales.

Nuestra Sociedad Mexicana de Neurología y Psiquiatría, que se ha destacado a lo largo de los años por su compromiso con la academia y la investigación, asume los nuevos retos que esta época nos plantea. Es así que buscamos la interacción con organismos diversos que aporten a nuestro entendimiento del ser humano en su acepción neuropsicológica. De manera reciente y siguiendo esta postura, la nueva mesa directiva organizó un evento que fue recibido con inmenso interés Ilamado el Arte y la Salud Mental. Interacciones con literatos, músicos y cineastas abrieron un foro de discusión sumamente enriquecedor acerca de la percepción, el sistema nervioso y los procesadores mentales de la creatividad humana. En esta misma tónica, nuestro congreso anual se llevó a cabo los primeros días del mes de septiembre, en conjunto con la PMG del Centro Médico ABC "Psiquiatría de enlace" y el Instituto Nacional de Neurología y Neurocirugía "Manuel Velasco Suárez". El tema del Congreso es "Responsabilidad Social de las Neurociencias" y durante el desarrollo del mismo se tocaron temas que, evidentemente, suman los saberes de distintas áreas del conocimiento humano. El 21 de octubre tendremos un evento que se centrará en las distintas polémicas que el tema del Cannabis despierta constantemente en nuestros medios. Para ello, contaremos con la presencia de un psiquiatra, un investigador, un abogado y un representante de instituciones gubernamentales, quienes debatirán acerca de las distintas complejidades que rodean al tema de la legalización de los productos cannabinérgicos.

Nuestra sociedad sigue comprometida con el desarrollo académico y con la difusión del conocimiento que parte de las ciencias neurológicas, las ciencias psiquiátricas y psicológicas y con todas las ciencias afines que impulsan la interacción respetuosa, digna y científica al servicio de un saber más completo. Durante el presente bienio, el deseo de esta mesa directiva es fomentar mayormente las reuniones multidisciplinarias que nos permitan a todos enriquecer nuestro acervo científico con retos que vayan más allá de nuestro quehacer cotidiano.

Correspondencia:

E-mail: david.szydlo@gmail.com 